\title{
O PORTUGUÊS LÍNGUA NÃO MATERNA NA UNIVERSIDADE FEDERAL DO ESPÍRITO SANTO: UM BREVE HISTÓRICO
}

\author{
EL PORTUGUÉS COMO LENGUA EXTRANJERA EN LA UNIVERSIDAD FEDERAL \\ DE ESPÍRITO SANTO: UNA BREVE HISTORIA
}

\author{
PORTUGUESE AS A NON-NATIVE LANGUAGE AT THE FEDERAL UNIVERSITY \\ OF ESPÍRITO SANTO: A BRIEF HISTORY
}

\author{
Renata Rocha Vieira de MELLO ${ }^{1}$ \\ Cláudia Jotto KAWACHI-FURLAN ${ }^{2}$
}

RESUMO: O objetivo deste artigo é discutir o histórico do Português Língua Não Materna (PLNM) na Ufes, sobretudo no âmbito do Departamento de Línguas e Letras e do Núcleo de Línguas, bem como as configurações e concepções teórico-metodológicas adotadas ao longo de seus principais períodos. Observamos que as principais ações de PLNM na instituição estão relacionadas com a oferta de cursos para a comunidade. Tais cursos passaram por mudanças significativas, tanto na organização quanto na concepção de língua(s) e de ensino, chegando a práticas de ensino e de aprendizagem embasadas no conceito de língua-cultura (MENDES, 2011, 2015, 2018), que influenciaram o desenvolvimento de cursos e usos de materiais didáticos com foco na visão intercultural. Analisar esse histórico do PLNM na Ufes é essencial para que possamos exigir políticas que não sejam restritas à oferta de cursos, mas que contemplem a formação docente e a institucionalização do PLNM na universidade.

PALAVRAS-CHAVE: Políticas linguísticas. Interculturalidade. Português língua não materna.

RESUMEN: El propósito de este artículo es discutir la historia del Portugués como Lengua Extranjera (PLE) en la Ufes, especialmente el relacionado con el Departamento de Lenguas y Letras y el Centro de Idiomas, así como las configuraciones y concepciones teóricas y metodológicas adoptadas a lo largo de sus principales periodos. Notamos que las principales acciones de PLE en la institución están relacionadas con la oferta de cursos a la comunidad. Dichos cursos sufrieron cambios significativos en su organización y sus concepciones de lengua(s) y enseñanza de lenguas, alcanzando prácticas de enseñanza y aprendizaje basadas en el concepto de lengua-cultura (MENDES, 2011, 2015, 2018), lo que incidió en el desarrollo de cursos y usos de materiales didácticos con perspectiva intercultural. El análisis de la historia del PLE en la Ufes es fundamental para exigir politicas que no se limiten a la oferta de cursos, sino que aborden la formación docente y la institucionalización del PLE en la universidad.

1 Universidade Federal do Espírito Santo (UFES), Vitória - ES - Brasil. Mestre em Estudos Linguísticos (UFES). ORCID: https://orcid.org/0000-0002-6567-3551.E-mail: renata.rvmello@gmail.com

${ }^{2}$ Universidade Federal do Espírito Santo (UFES), Vitória - ES - Brasil. Professora no Departamento de Línguas e Letras. ORCID: https://orcid.org/0000-0003-4699-6774. E-mail: claudia.furlan@ufes.br 
PALABRAS CLAVE: Políticas lingüisticas. Interculturalidad. Portugués como lengua extranjera.

ABSTRACT: The aim of this article is to discuss the history of Portuguese as a non-native language (PNNL) at Federal University of Espirito Santo, mainly within the Languages and Literature Department and the Language Center, as well as the configurations and theoretical and methodological concepts adopted throughout the specific period of time. We noticed that the main actions of PNNL at the institution are related to the offer of courses to the community. Those courses went through significant changes regarding their organization and their concept of language(s) and language teaching, focusing on teaching and learning practices based on the concept of language-culture (MENDES, 2011, 2015, 2018), which influenced the development of courses and the use of teaching materials with an intercultural perspective. The analysis of the PNNL history at Ufes is essential to demand policies that are not restricted to courses, but that also approach teacher education and institutionalization of PNNL at the university.

KEYWORDS: Language policies. Interculturality. Portuguese as a non-native language.

\section{Introdução}

Este artigo é um desdobramento de um estudo de caso realizado em uma pesquisa de mestrado $^{3}$ no Programa de Pós-Graduação em Linguística (PPGEL) da Universidade Federal do Espírito Santo (Ufes). Por meio deste artigo, pretendemos discutir, em linhas gerais, o histórico do Português Língua Não Materna (PLNM) na Ufes - sobretudo no âmbito do Departamento de Línguas e Letras (DLL) -, bem como as configurações e concepções teórico-metodológicas adotadas ao longo de seus principais períodos. Para isso, foram adotadas, como procedimentos metodológicos de geração de dados, entrevistas semiestruturadas junto a alguns dos sujeitos envolvidos nesses períodos, bem como a análise documental. Os dados gerados foram categorizados de acordo com os temas e momentos considerados mais relevantes para a (re)construção histórica do PLNM na universidade.

A Ufes, sobretudo no âmbito do DLL, tem sido espaço de ofertas de cursos de PLNM desde a década de 1970. Posteriormente, de 1997 a 20194, as ofertas foram concentradas por meio do curso "Português Língua Estrangeira" onde hoje é o Núcleo de Línguas da Ufes, setor integrante e permanente do Centro de Ciências Humanas e Naturais (CCHN) da universidade. Observamos que os cursos oferecidos nesses dois grandes períodos (de 1970 a

3 "A formação de professores de Português Língua Estrangeira/Segunda Língua na Universidade Federal do Espírito Santo" (VIEIRA DE MELLO, 2021).

${ }^{4}$ Ao final do primeiro semestre de 2019, o curso entrou em reformulações, deixando de ser ofertado a partir de 2019/2 sem que houvesse, até o período de conclusão da pesquisa, uma previsão de retomada.

Rev. EntreLínguas, Araraquara, v. 7, n. esp. 6, e021144, dez. 2021. 
1997 e 1997 a 2019) se distinguem em diversos aspectos, como estrutura, público-alvo, obrigatoriedade a graduandos estrangeiros, concepções teórico-metodológicas, entre outros. Em relação às concepções teórico-metodológicas, o curso, com início na década de 1970, foi marcado por visões de língua mais estruturalistas e, embora essa tendência tenha sido adotada também nas primeiras ofertas do Núcleo de Línguas, os objetivos do público-alvo motivaram a adoção de abordagens teórico-metodológicas mais comunicativas. Além disso, cada vez se desenvolveu, nas práticas de ensino e aprendizagem, a visão intercultural a partir da concepção de língua-cultura (MENDES, 2011; 2015; 2018).

Outras iniciativas de ensino de português para estrangeiros PLNM também foram observadas na Ufes. É o caso do curso ofertado pela Secretaria de Relações Internacionais (SRI) da universidade, disponível até 2019. Há também o Curso de Português e Cultura Brasileira, oferecido pela Comissão Permanente de Direitos Humanos, em parceria com a Pró-Reitoria de Extensão (Proex) e com a Cátedra Sérgio Vieira de Mello, em um projeto de extensão intitulado 5 "Construção de Cidadania por Meio da Língua". O curso é voltado, sobretudo, a estrangeiros refugiados de países em conflito e que necessitam aprender a língua e cultura brasileiras. Essas iniciativas, no entanto, não constarão no recorte da pesquisa aqui explanada, por não estarem estritamente relacionadas ao DLL.

Ao nos debruçarmos sobre o histórico do PLNM na Ufes, observamos a relevância do DLL e do Núcleo de Línguas ao concentrarem ações de desenvolvimento do PLNM na universidade. Ainda assim, julgamos que a institucionalização do PLNM é fundamental para que esse campo seja contemplado nas políticas linguísticas da Ufes, visando "conduzir ações concretas de interesse público relativo à(s) língua(s) que importam para o povo de uma nação, de um estado ou ainda, instâncias transnacionais maiores" (RAJAGOPALAN, 2013, p. 21).

Portanto, o objetivo deste artigo, ao traçar o histórico do PLNM na instituição, é discutir a necessidade de implementação de ações concretas de PLNM. Para tanto, é preciso que o PLNM não seja compreendido apenas como sinônimo da oferta de cursos, mas abarque também o papel dessa língua nas políticas da universidade, bem como nas propostas planejadas e dialogadas voltadas à formação docente.

A pesquisa aqui exposta consta como uma tentativa de contribuição para a área de PLNM, sobretudo o da Universidade Federal do Espírito Santo, pois percebemos, na Ufes,

${ }^{5}$ No entanto, nesse período, o curso deixou de ser uma obrigatoriedade aos alunos estrangeiros de graduação da universidade. 
escassez alarmante de pesquisas ${ }^{6}$ voltadas para essa área. Esperamos, também, que este artigo ajude na divulgação do histórico do PLNM da Ufes, o que pode servir de contextualização para futuros pesquisadores interessados em PLNM.

\section{Procedimentos metodológicos}

Conforme mencionado, este trabalho caracterizou-se como um estudo de caso, investigação por meio da qual é possível explorar e descrever, de maneira mais detalhada e aprofundada, "um determinado evento ou situação, sem a preocupação de descobrir uma verdade universal e generalizável" (LEFFA, 2006, p. 15).

A geração de dados envolveu análise documental e entrevistas semiestruturadas. Foram, assim, analisados documentos que regem o Núcleo de Línguas da Ufes e alguns documentos que norteiam as iniciativas de PLNM nos âmbitos do DLL da universidade. Além disso, foram realizadas entrevistas presenciais semiestruturadas, utilizando-se gravações de áudio, junto a alguns dos sujeitos envolvidos no ensino e na formação de professores de PLNM: docentes formadores de PLNM (sendo um membro do Núcleo de Línguas da Ufes e outro, do DLL da universidade) e (ex) professores/estagiários do ensino de PLNM no âmbito da universidade - em especial, do Núcleo de Línguas. Cada professora ou professor de PLNM entrevistada(o) foi bolsista de um período diferente entre 2014 e 2019 - com exceção da professora que atuou no PLNM da Ufes na década de 1970. O quadro a seguir traz um breve resumo dos perfis dos participantes.

Tabela 1 - Participantes e respectivas atuações na área de PLE/L2 da Ufes

\begin{tabular}{|l|l|}
\hline Participante $^{7}$ & \multicolumn{1}{|c|}{ Atuação } \\
\hline Ester Abreu & Ex-professora de PLNM na Ufes (décadas de 1970 e 1980) \\
\hline Sandro & Formador; professor do DLL; ex-professor de PLNM (décadas de 1970 e 1980) \\
\hline João & Ex-assessor de PLNM no Núcleo de Línguas (2014 a 2019) \\
\hline Carla & Ex-professora estagiária de PLE/L2 no Núcleo de Línguas (2014 a 2016) \\
\hline Hanna & $\begin{array}{l}\text { Ex-professora estagiária de PLE/L2 no Núcleo de Línguas (2016 a 2018); bolsista no } \\
\text { programa IsF (2018) }\end{array}$ \\
\hline
\end{tabular}

Fonte: Acervo das autoras

${ }^{6}$ Até o momento em que este texto estava sendo elaborado, encontramos apenas um registro de uma dissertação de mestrado com foco em PLNM no Programa de Pós-graduação em Linguística da Universidade.

${ }^{7}$ Devido ao fato de suas atividades serem recentes e/ou atuais no PLNM da Ufes, inserimos nomes fictícios aos participantes Sandro, João, Carla e Hanna a fim de preservar suas identidades.

Rev. EntreLínguas, Araraquara, v. 7, n. esp. 6, e021144, dez. 2021 
Os dados gerados puderam ser categorizados de forma a delinearem dois grandes períodos de PLNM na Ufes: o período que se iniciou na década de 1970 e se estendeu à regulamentação, em 1997, do que veio a ser o atual Núcleo de Línguas da Ufes; e de 1997 ao final do primeiro semestre de 2019 - sendo que, de 2014 a 2019, o curso tomou sua última configuração, com abordagens de ensino e aprendizagem mais diversificadas. Os itens a seguir tratarão de cada um desses períodos.

\section{O ensino de PLNM na Universidade Federal do Espírito Santo: origens}

Historicamente, as primeiras ofertas de ensino de PLNM pelo Departamento de Línguas e Letras na Ufes remontam aos anos de 1970. Nessa década, na Universidade de São Paulo (USP) e na Universidade Estadual de Campinas (Unicamp), foram criados os primeiros cursos de PLNM do Brasil, sendo que a área contou também com a criação de uma disciplina e contratação de professores pesquisadores para esse quadro. Até então, o PLNM como área de pesquisa e atuação profissional ainda havia dado alguns passos iniciais, como a publicação, em 1957, do livro O ensino de Português para estrangeiros (1957), de Mercedes Marchant, e quando se reuniu, em Austin, Texas, uma equipe contendo estadunidenses e brasileiros para a elaboração de um manuscrito para uma edição experimental de Modern Portuguese, vinculada à Modern Language Association of America, publicada em 1966.

Tendo em vista a dificuldade na recuperação de documentos referentes ao período, a (re)construção dos processos históricos do PLNM na Ufes se deu principalmente por meio de entrevista junto à Prof. ${ }^{a}$ Dra. Ester Abreu Vieira de Oliveira, primeira professora a lecionar PLNM na Ufes, função exercida durante 16 anos desde essa década. O então público-alvo consistia tanto em estudantes da universidade, quanto na comunidade externa, composta principalmente por trabalhadores de multinacionais estrangeiras e seus familiares. A obrigatoriedade do curso de PLNM - o qual, na época, totalizava três anos - aos universitários estrangeiros foi posta devido às dificuldades linguístico-culturais enfrentadas por eles em seus cursos de graduação na Ufes. Sandro, professor do DLL, explica como esses cursos eram organizados:

O curso era constituído de três disciplinas, de 75 horas cada uma: Português Básico, Português Intermediário e Português Avançado. [...] No primeiro semestre, os alunos faziam Geografia, História e Português. E nos dois anos subsequentes, aliás, nos dois semestres subsequentes, faziam Português Intermediário e Português Avançado. Eu fiz parte do grupo de trabalho [...] que deu aula para um grupo de alunos [de níveis avançados] $e$ 
eu fiz parte do grupo com a responsabilidade, de certo modo, pela oferta da professora Ester Abreu [...]. E logo na sequência, lá pelos anos 1990, a universidade começou a organizar uma proposta de oferta de cursos de linguas estrangeiras para a comunidade (Sandro, entrevista).

As aulas desse curso, cujas turmas eram compostas por alunos de diversas nacionalidades e culturas, voltavam-se principalmente aos aspectos fonéticos e fonológicos do português brasileiro, havendo constantemente o uso, em laboratórios, de aparelhos em cabines para audição de materiais gravados em português e repetição das palavras. Em relação a esses instrumentos e concepções teórico-metodológicas a eles relacionadas, Paiva (2015, p. 06) explica que, embora tenham sido uma forte tendência na época, esses tipos de laboratórios não lograram muito sucesso por conta da rigidez das instalações e, sobretudo, dos "princípios linguísticos e de aprendizagem que lhe davam suporte: o conceito de língua como conjunto de estruturas sintáticas e de aprendizagem, como criação de hábitos automáticos”, conceitos esses que perderam força diante de modelos de ensino e aprendizagem que visavam à interação e comunicação. De fato, a professora Ester Abreu informou, durante a conversa, que, logo após sua atuação, os aparelhos foram descartados pela Ufes.

No entanto, o trabalho realizado resultou na publicação, pela professora, do livro didático Português para Estrangeiros: 31 lições (1981). A publicação, que conta atualmente com uma versão digital ${ }^{8}$ de 2019, é, portanto, uma das obras pioneiras para a área de PLNM, e reflete bastante as concepções teórico-metodológicas colocadas em prática pela professora na época: são lições e atividades estruturais então adotadas em sala de aula, bem como resumos de gramática normativa, noções de fonética e glossários comparativos envolvendo palavras do português e dos idiomas alemão, inglês, espanhol, francês, italiano e japonês (OLIVEIRA, E., 2019).

Ao final da década de 1990, a regulamentação de um projeto que reuniu, em um só espaço físico, iniciativas de ensino de línguas da universidade trouxe mudanças significativas, inclusive para o ensino e a aprendizagem de PLNM. Esse, portanto, será o assunto do item a seguir.

\section{O PLNM no Núcleo de Línguas da Ufes}

Conforme mencionado anteriormente, foram reunidas, em 1997, as iniciativas de ensino de línguas relacionadas ao DLLe à Proex da universidade - tal como o curso de PLNM

${ }^{8}$ Disponível em: https://www.academia.edu/39970930/Portugu\%C3\%AAs_para_estrangeiros_Ester. Acesso em: 10 mar. 2020. 
conduzido pela professora e demais professores a ela subsequentes - a partir da regulamentação do então "Cursos de Línguas para a Comunidade" (CLC). Porém, algumas mudanças nesse espaço ainda estariam por vir. Em 2011, após uma reorganização para o atendimento de novas demandas da universidade, o CLC tornou-se o "Centro de Línguas: Projeto Integrado de Ensino, Extensão e Pesquisa”. No entanto, durante esse período, por consistir em um projeto, a instituição vivia relativa instabilidade devido à necessidade de renovações constantes, o que fez com que o projeto se regulamentasse em 2016, pela resolução n 39/2016, de 14 de outubro de 2016, e se tornasse "Núcleo de Línguas: Ensino, Extensão e Pesquisa" da Ufes, o qual encontra-se subordinado ao Centro de Ciências Humanas e Naturais (CCHN) da Ufes (CESTARO, 2017).

Dessa maneira, de 1997 até 2019, o PLNM foi, na universidade, uma das línguas modernas contempladas pelo Programa Curso de Línguas por meio do curso regular intitulado "Português para Estrangeiros". Vale ressaltar que, na década de 1990, ainda em meio a restritas políticas de expansão e internacionalização da língua portuguesa brasileira, multiplicaram-se as pesquisas, eventos e publicações de materiais na área de PLNM. Alguns dos marcos históricos que contribuíram para isso foram a assinatura do Tratado de Assunção, em 1991, que deu origem ao Mercado Comum do Sul (Mercosul), sendo o Português e o Espanhol seus idiomas oficiais; a fundação da Sociedade Internacional de Português Língua Estrangeira (SIPLE) em 1992, durante o III Congresso Brasileiro de Linguística Aplicada, realizado na Unicamp; a criação, em 1993, do Certificado de Proficiência em Língua Portuguesa para Estrangeiros (Celpe-Bras), exame brasileiro oficial para certificação da proficiência em PLNM e uma das principais políticas brasileiras de promoção da língua portuguesa do Brasil; e o estabelecimento da Comunidade dos Países de Língua Portuguesa (CPLP) em 1996.

$\mathrm{Na}$ Ufes, o público-alvo do curso "Português Língua Estrangeira" incluía a comunidade externa (imigrantes/público estrangeiro em geral com idade mínima de 15 anos) e os estudantes com matrícula regular na Ufes, por força de convênios e projetos, como o Programa de Estudantes-Convênio de Graduação (PEC-G) ${ }^{9}$. Os objetivos gerais do curso, conforme constava na página on-line do Núcleo de Línguas ${ }^{10}$, envolviam

\footnotetext{
${ }^{9}$ O curso de PLNM do Núcleo contava com professores estagiários bolsistas, alunos de graduação dos cursos de Letras, e com um assessor, ou seja, um professor efetivo do Núcleo que acompanhava mais diretamente o trabalho dos professores estagiários, promovendo reuniões periódicas, consultoria, reflexões de formação, além de atendimento ao público discente.

${ }^{10}$ Retirado de: http://www.nucleodelinguas.ufes.br/portugues-lingua-estrangeira-ple-regular. Acesso em: 26 ago. 2019.
} 
Possibilitar aos alunos a aquisição do português do Brasil, vivenciando em processo de imersão os valores culturais brasileiros, veiculados linguisticamente em situações e contextos relevantes e diversificados de uso; além de oferecer ao aluno o aprendizado e a prática das habilidades orais e escritas exigidas no Celpe-Bras ${ }^{11}[\ldots]$ (UFES, 2013).

Estamos cientes que as ações mais recentes, não vinculadas explicitamente ao DLL, são decorrentes do processo de internacionalização das universidades brasileiras. Esses cursos voltados para programas como o PEC-G podem ser considerados um importante passo para a internacionalização de universidades a ser feita "em casa", na qual estudantes e profissionais estrangeiros aqui aprendem a produzir conhecimento também em língua portuguesa (GUIMARÃES; FINARDI; CASOTTI, 2019).

Por meio de entrevista junto a João, o último assessor do curso de PLNM no Núcleo de Línguas, percebemos que as ofertas de PLNM no período de 1997 a 2019 também puderam ser categorizadas de acordo com suas estruturas e as abordagens utilizadas. De 1997 a meados de 2014, estruturalmente, o curso era dividido em semestres letivos, o que, para o assessor, não era compatível com o público:

o perfil do nosso público, não cabia isso. [...] Porque as pessoas estrangeiras tinham que voltar pro trabalho, voltar pro país [...] para poder pegar visto, tinha que sair por algum motivo, de viajar por algum motivo. Tinha pessoas também que eram missionárias, que tinham que sair pra um outro estado, pro Amazonas e voltar. Então, o perfil, a gente percebeu, nessa história toda, até dois mil e... um pouquinho antes [de eu entrar na coordenação], que não... era o ideal pro estrangeiro que a gente tem que trabalhar, nosso público. (João, entrevista).

Esse período também contou com uma especificidade em relação à abordagem de ensino e aprendizagem. $\mathrm{O}$ ex-assessor relatou que o estruturalismo era bastante forte, o que, para o público da época, não era tão adequado, principalmente devido ao fato de se tratar de um público que se interessava em aprender a língua para utilizá-la no dia a dia, em situações mais reais de comunicação:

Então, [...] [em 2014] fizemos uma pesquisa. Cem por cento! cem por cento [dos alunos] falou que a aula era muito estrutural [...]: "A gente aprende muita gramática!”, "A gente aprende muito... uma lista de gramática”. [...] Naquela época, eles queriam falar; eles queriam se comunicar com as pessoas na rua, eles queriam ir na Rua da Lama ${ }^{12}$, tomar uma cervejinha (João, entrevista).

${ }^{11}$ A Ufes se credenciou como Posto Aplicador do Exame Celpe-Bras em 2016, sendo o Núcleo de Línguas um importante espaço para esse processo.

${ }^{12}$ Point boêmio no bairro de Jardim da Penha, em Vitória.

Rev. EntreLínguas, Araraquara, v. 7, n. esp. 6, e021144, dez. 2021. e-ISSN: $2447-3529$ 
Até então, o livro didático utilizado era o Ponto de encontro - Portuguese as a world language ${ }^{13}$, da editora Pearson. Ainda segundo o ex-assessor, o livro Ponto de Encontro, por ser bilíngue (inglês/português) e fazer muito uso de atividades, segundo ele, descontextualizadas e distantes do uso real de comunicação, não atendia às demandas dos alunos no Núcleo:

[...] nós estávamos usando um livro bilíngue, que era... excluía um pouquinho os outros idiomas, [...] em um país que nem todos liam inglês, nem todos os estrangeiros conseguiam ler inglês, e ai eu percebi que não era pro nosso público. A gente vai usar no Brasil, um livro que se usa nos Estados Unidos, pra inglês ver? [...] Então, assim, por exemplo, no inglês, lá tinha a estrutura, a explicação, a orientação [...], e ai tinha gramática comparativa, essas coisas. E aí eu percebi "Não, não é o livro. É grosso, não é nossa metodologia, não encaixava na nossa metodologia" porque era muito... ainda é muito estrutural. [...] Não era muito maleável, muito criativo [para situações além das previstas nas atividades]. (João, entrevista).

Em 2014, as reformulações em busca de um curso mais compatível para com o público incluíram mudanças na estrutura, na(s) abordagem(ns) e no(s) material(is) didático(s). O curso foi dividido em pequenos módulos de 30 horas, carga horária mínima e suficiente para certificação, o que era mais adequado para o público.

Além da mudança estrutural, abordagens e métodos também sofreram ajustes em torno de uma maior flexibilização para atender as necessidades que viriam a surgir dos alunos. Para isso, a partir de 2014, a cada seleção de estagiários, maior e mais expressivo foi o período de formação antes ("pré-estágio") e durante a atuação, a fim de familiarizar esses estudantes (que, em geral, eram do curso de Letras Português) com as metodologias principais adotadas nos cursos do Núcleo, situadas na abordagem comunicativa - e, no caso do curso de PLE/L2, a abordagem comunicativa associada à perspectiva intercultural, a ser discutida em um próximo item. Ainda, no campo de formação de professores de PLNM, o DLL passou a oferecer, no curso de Licenciatura em Letras, a disciplina optativa "Português Língua Estrangeira" - ofertada com mais frequência a partir de 2015 e 2016, principalmente devido ao processo de credenciamento, em 2016, do Núcleo de Línguas como um Posto Aplicador do Exame Celpe-Bras e o consequente fomento da área.

Se, no início, "a" abordagem comunicativa era o foco, aos poucos, essa concepção foi se flexibilizando para, cada vez mais, ir ao encontro das necessidades e objetivos dos estudantes:

${ }^{13}$ Livro das autoras Clémence M. C. Jouët-Pastré, Anna M. Klobucka, Patrícia Isabel Santos Sobral, Maria Luici De Biaji Moreira e Amélia P. Hutchinson. 
nós começamos a fazer treinamento de pessoal pra saber das abordagens. Porque [...] já aconteceu aqui de uma estagiária nossa dar uma aula, perceber a necessidade específica daquele tal o aluno e modificar a metodologia, pegar um método de uma abordagem diferente pra utilizar na sala de aula [...] E aquilo funcionou para aquele individuo. [...] Então o que eu coloquei na cabeça das pessoas na época foi que aquilo que eles estavam dando existe em termos de abordagem, [...] nós podemos variar. Existe a abordagem comunicativa que ela abraça todas as outras, é mais solidária. (João, entrevista).

\section{O livro didático passou a ser o Novo Avenida Brasil - Curso Básico de Português} para Estrangeiros ${ }^{14}$, da Editora Pedagógica e Universitária (EPU). No entanto, apesar da mudança e adoção do Novo Avenida Brasil, os professores de PLE/L2 ainda precisavam criar e/ou adaptar boa parte de seus materiais, como destacou a ex-estagiária Hanna:

Nós tínhamos um material na época que era o Novo Avenida Brasil, um livro que a gente usava, só que é um livro que apesar de se dizer comunicativo a gente via ainda muitas lacunas, né, assim... aparecia assim muitos exercícios gramaticais no meio e a gente se perguntava o que fazer na aula invés de usar isso [...] porque a gente sabia que os alunos às vezes não precisavam daquilo, eles precisavam de situações em que eles vão precisar usar a língua. (Hanna, entrevista).

De qualquer maneira, pudemos perceber, diante das reformulações, uma atitude crítica que envolveu uma escolha consciente de materiais a partir do contexto de atuação, com foco nas necessidades das turmas. A adaptação de materiais e a constante preocupação em relação ao perfil dos alunos (suas dificuldades, demandas e objetivos, etc.) como motor para a escolha das estratégias a serem utilizadas são posturas que se relacionam a uma prática ancorada na realidade da sala de aula e seus sujeitos. Ou seja, trata-se de uma atuação em que o professor possui a autonomia necessária para considerar, no processo de ensino e de aprendizagem, o contexto de ensino (aspectos linguísticos, socioculturais e políticos, entre outros) e construir suas teorias e práticas, as quais se diversificam de acordo com as necessidades surgidas (KUMARAVADIVELU, 2001; LEFFA, 2012).

Vale lembrar que a adaptação e criação de materiais didáticos é de suma importância para a formação de professores, conforme demonstrado por Mozer e Kawachi-Furlan (2019). Por meio da reflexão sobre livros didáticos disponíveis nos cursos (potencialidades, limitações) em relação ao contexto de ensino, aprendizagem e uso, a criação e adaptação de materiais prepara os professores para irem além do papel de meros consumidores passivos desses materiais, oferecendo-lhes oportunidades para que se tornem mais ativos nesse e,

${ }^{14}$ Escrito por Emma Eberlein O. F. Lima, Lutz Rohrmann, Tokiko Ishihara, Cristián González Bergweiler. 
consequentemente, romperem com a perspectiva tecnicista de aplicação mecânica, em aula, daquilo que é prescrito pelo material (MOZER; KAWACHI-FURLAN, 2019).

Durante todo o ano de 2019, ofertou-se o curso de português vinculado ao Programa Idiomas sem Fronteiras (IsF) e, portanto, seu público-alvo consistia em estudantes matriculados na universidade. Em todos esses momentos, os professores eram estagiários bolsistas, estudantes de graduação em Letras. ${ }^{15}$

Tendo em vista os aspectos contextuais do estudo de caso e considerando a modalidade de pesquisa adotada, o item a seguir tem por objetivo discutir mais a fundo a concepção intercultural adotada no curso de PLNM do Núcleo.

\section{O desenvolvimento da concepção intercultural no PLNM do Núcleo}

Um aspecto relevante em relação ao curso de PLNM do Núcleo de Línguas que, segundo o ex-assessor, progressivamente permeou os temas das reuniões junto aos estagiários no período de 2014 a 2019 foi a implementação e o desenvolvimento do pensamento intercultural (MENDES, 2011; 2018). Para Carla, uma das professoras estagiárias da época, a construção da concepção de ensino de português como língua-cultura consta como uma exigência ao ensino de PLNM, junto ao tema da língua em uso, para além da norma-padrão da língua. Muito discutido e defendido em vários trabalhos de Edleise Mendes (2011; 2015), o conceito de língua-cultura perpassa uma concepção de língua para além da concepção de instrumental, pois

[...] a língua é um símbolo, um modo de identificação, um sistema de produção de significados individuais, sociais e culturais, uma lente através da qual enxergamos a realidade que nos circunda. Ao estruturar nossos pensamentos e ações, ela faz a mediação entre as nossas experiências e a do outro com o qual interagimos socialmente através da linguagem, auxiliandonos a organizar o mundo à nossa volta [...] (MENDES, 2011, p. 143).

A partir dessa concepção, a autora, em defesa da adoção da chamada Abordagem Comunicativa Intercultural (ACIN) no ensino de PLNM, descarta a ideia de cultura como algo que venha antes ou depois da língua, ou mesmo como algo que contenha ou esteja contida na língua. Para ela, não há separações dos limites de onde começa uma e termina

15 Atualmente, o curso de português do IsF já não é ofertado devido ao encerramento do Programa em 2019 pelo MEC. Em fevereiro de 2020, no entanto, foi inaugurado na Ufes o curso Pré-PEC-G, um preparatório para o Celpe-Bras voltado aos estrangeiros selecionados pelo PEC-G para ingressar em universidades brasileiras, tendo em vista que o exame é um pré-requisito para que eles possam cursar graduação e pós-graduação em universidades brasileiras. Para mais informações, consultar: http://www.ufes.br/conteudo/ufes-inaugura-cursopreparatorio-para-prova-de-proficiencia-em-portugues. Acesso em: 04 set. 2020. 
outra. No ensino de línguas, o cultural não deve ser tido apenas como um conjunto de conteúdos a ser introduzido de maneira justaposta a quaisquer outros da esfera linguística:

[...] Aprender uma língua como o português, por exemplo, seria mais do que dominar uma cultura de ilustração, mas aprender a estar socialmente em português, o que envolve muito mais coisas do que simplesmente o domínio de formas linguísticas e de curiosidades culturais sobre a língua-alvo. (MENDES, 2011, p. 143, grifo do autor).

Portanto, a autora assume a posição de denominar, como "língua-cultura", a línguaalvo dos processos de ensino e de aprendizagem e/ou a língua que media culturas diferentes. A língua-cultura seria, então, um "fenômeno social e simbólico de construção da realidade que nos cerca, $[\ldots]$ modo de construirmos nossos pensamentos e estruturarmos as nossas ações e experiências e partilharmos com os outros" (MENDES, 2011, p. 143-144). Esse sistema envolve, além de questões estruturais formais e de organização dessas estruturas, "um conjunto de ideias e pressupostos sobre uma das mais importantes dimensões da vida humana - a dimensão cultural." (MENDES, 2015, p. 204). Ou seja, aprendermos uma língua como o português implica em aprendermos os códigos linguísticos socioculturais verbais ou não verbais que a envolvem, bem como o que precisamos fazer para agir nessa língua e cultura, já que, segundo Mendes (2011, p. 144), “[...] a dimensão de uma língua, [...], e aqui o português, é o próprio lugar da interação, a própria instância na qual produzimos significados ao vivermos no mundo e com outros".

Apesar de, no início de sua atuação como assessor de PLNM da instituição, já haver, entre a equipe e nas aulas, a preocupação e o respeito para com a cultura do aluno estrangeiro, o ex-assessor a define como uma "preocupação natural", sem uma "teoria por trás", ou seja, de modo inconsciente. Foi em 2014 e 2015, a partir dos estudos junto à professora Regina Egito, ex-orientanda da professora Edleise Mendes na Universidade Federal da Bahia, e do aprofundamento sobre o assunto que a equipe passou a conhecer, de fato, a abordagem intercultural e a utilizá-la de maneira "eficiente" (João, entrevista).

O curso, então, procurou adotar a $\operatorname{ACIN}^{16}$ (MENDES, 2011; 2015; 2018) e, além de estudos em conjunto, os estagiários recebiam feedbacks do assessor para reflexão sobre as posturas em relação à cultura dos estudantes:

à medida que a gente assistia [à aula], a gente dava o feedback: "Ah, essa parte você podia ter feito isso"; "Isso aqui é legal"; [...] "Olha, cuidado

16 Esse processo de "adoção consciente" da ACIN pelo PLNM do Núcleo, relatado por João, remete-nos à discussão da indissociabilidade entre teoria e prática descrito por Souza (2001) pois, a partir da associação da prática aos estudos teóricos, as ações se ressignificaram e tomaram uma dimensão de prática reflexiva.

Rev. EntreLínguas, Araraquara, v. 7, n. esp. 6, e021144, dez. $2021 . \quad$ e-ISSN: 2447-3529 
com o que for falar" - ai vem a nossa preocupação [da fala] também com o estrangeiro. Então a gente percebeu quando a gente começou a entender a interculturalidade e perceber as diferenças [...] das formas de aprender de cada [cultura]. Do Oriente e do Ocidente, por exemplo [...] (João, entrevista).

O entrevistado cita ainda que o desafio aumentava na proporção em que o Núcleo recebia alunos das mais diversas origens. Por isso, a equipe se esforçava em se capacitar no sentido de construir, junto aos alunos, percepções sobre estereótipos e preconceitos inclusive em relação ao Brasil.

A complexidade desse contexto de alta diversidade cultural é uma das caracterizações feitas por Mendes (2018) do cenário mundial atual e, portanto, das salas de aula - como, em geral, são as de PLNM. A autora, então, defende uma formação de professores que prepare o professor para atuar em contextos multilíngues que coloquem em foco o ensino de Português como uma língua de mediação e inclusão. Para isso, faz-se necessário o estabelecimento do diálogo entre culturas a fim de que se mitiguem questões problemáticas como as relatadas pelo entrevistado.

\section{Considerações finais}

Este artigo teve como objetivo discutir os principais marcos históricos do PLNM na Universidade Federal do Espírito Santo. Com base nesse levantamento, observamos a importância do Departamento de Línguas e Letras e do Núcleo de Línguas na promoção de ações voltadas ao PLNM, desde 1990 a 2019, sobretudo com relação à oferta de cursos para a comunidade acadêmica e para a comunidade externa.

A proposta de cursos passou por mudanças significativas, tanto na organização (carga horária, público-alvo, etc.) quanto na concepção de língua(s) e de ensino, tendo iniciado com uma perspectiva mais estrutural de língua que influenciava a escolha dos livros didáticos e chegando a práticas de ensino e de aprendizagem embasadas no conceito de língua-cultura (MENDES, 2011; 2015; 2018), que levaram ao desenvolvimento do curso e a seleção e uso de materiais didáticos com foco na visão intercultural. Observamos, também, uma atenção especial à formação docente nesse processo, com iniciativas do DLL por meio da oferta de disciplina optativa e com proposições do NL voltadas à preparação dos professores estagiários antes e durante sua atuação como professores de PLNM.

Estamos cientes de que há outras ações sendo desenvolvidas na universidade. No entanto, por conta da representatividade do DLL e do NL nesse campo e da limitação de 
espaço neste artigo, enfocamos nas propostas desses contextos. Acreditamos que compreender esse histórico do PLNM na Ufes é essencial para que possamos exigir políticas que não sejam restritas à oferta de cursos de línguas, mas que contemplem a formação docente e o desenvolvimento de políticas linguísticas visando a institucionalização do PLNM na universidade. Esperamos que, por meio deste artigo, o PLNM da Ufes seja alvo de maior divulgação na área, bem como que este trabalho sirva de subsídios para pesquisas futuras que abordem o PLNM no Espírito Santo e nas demais universidades.

\section{REFERÊNCIAS}

FILHO, J. C. P. A. Dimensões comunicativas no ensino de línguas. Campinas, SP: Pontes Editores, 2015.

CESTARO, J. C. O ensino de italiano no Núcleo de Línguas da Ufes. 2017. Trabalho de Conclusão de Curso (Licenciatura em Letras Português - Italiano) - Universidade Federal do Espírito Santo, Vitória, 2017.

GUIMARÃES, F. F.; FINARDI, K. R.; CASOTTI, J. B. C. Internationalization and Language Policies in Brazil: What is the Relationship? Revista Brasileira de Linguística Aplicada, Belo Horizonte, v. 19, n. 2, p. 295-327, abr./jun. 2019. Disponível em: https://www.scielo.br/scielo.php?script=sci_arttext\&pid=S1984\%2063982019000200295\&tlng=en. Acesso em: 04 set. 2020.

KUMARAVADIVELU, B. Toward a postmethod pedagogy. TESOL Quartely, v. 35, n. 4, p. 537-60, 2001.

LEFFA, V. J. Aprendizagem de línguas mediada por computador. In: LEFFA, V. L. (org.). Pesquisa em Lingüística Aplicada: temas e métodos. Pelotas, RS: Educat, 2006. p. 5-30.

LEFFA, V. J. Ensino de línguas: passado, presente e futuro. Revista de Estudos da Linguagem, Belo Horizonte, v. 20, n. 2, p. 389-411, jul./dez. 2012. Disponível em: https://periodicos.letras.ufmg.br/index.php/relin/article/view/2755. Acesso em: 20 maio 2019.

MENDES, E. A ideia de cultura e sua atualidade para o ensino-aprendizagem de LE/L2. EntreLínguas, Araraquara, v. 1, n. 2, p. 203-221, jul./dez. 2015.

MENDES, E. Formar Professores de Português LE/L2 na universidade: desafios e projeções. In: KFOURI-KANEOYA, M. L. C. (org.). Português língua estrangeira em contextos universitários: experiências de ensino e de formação docente. Campinas: Mercado de Letras, 2018. v. 1. p. 65-94.

MENDES, E. O português como língua de mediação cultural: por uma formação intercultural de professores e alunos de PLE. In: MENDES, E. (org.). Diálogos interculturais: ensino e formação em português língua estrangeira. Campinas, SP: Pontes, 2011. p. 139-158. 
MOZER, I. P.; KAWACHI-FURLAN, C. J. Not by the book: the experience of designing teaching material for an English for Specific Purposes course in the Program Languages without Borders. Revista Digital dos Programas de Pós-Graduação do Departamento de Letras e Artes da UEFS, Feira de Santana, v. 18, n. esp., p. 145-162, out./dez. 2017.

PAIVA, V. L. M. O uso da tecnologia no ensino de línguas estrangeiras: breve retrospectiva histórica. In: JESUS, D. M.; MACIEL, R. F. (org.). Olhares sobre tecnologias digitais: linguagens, ensino, formação e prática docente. Campinas, SP: Pontes Editores, 2015. p. 21 34. Disponível em: https://www.veramenezes.com/techist.pdf. Acesso em: 03 ago. 2021.

RAJAGOPALAN, K. Política Linguística: do que é que se trata, afinal? In: NICOLAIDES, C. et al. (org.). Política e políticas linguísticas. Campinas, SP: Pontes Editores, 2013. p. 19-42.

SOUZA, N. A. A relação teoria-prática na formação do educador. Semina: Ciências Sociais e Humanas, Londrina, v. 22, p. 5-12, set. 2001.

MELLO, R. R. V. A formação de professores de Português Língua Estrangeira/Segunda Língua na Universidade Federal do Espírito Santo. 2021. Dissertação (Mestrado em Linguística) - Universidade Federal do Espírito Santo, 2021.

\section{Como referenciar este artigo}

MELlO, R. R. V. KAWACHI-FURLAN, C. J. O Português Língua Não Materna na Universidade Federal do Espírito Santo: um breve histórico. Rev. EntreLínguas, Araraquara, v. 7, n. esp. 6, e021144, dez. 2021. e-ISSN: 2447-3529. DOI: https://doi.org/10.29051/el.v7iesp.6.15424

Submetido em: 29/08/2021

Revisões requeridas em: 16/10/2021

Aprovado em: 30/11/2021

Publicado em: 28/12/2021 